\title{
Improving Conceptual and Procedural Knowledge of Prospective Teachers through Multisensory Approach: Experience from Indonesia
}

\author{
Yurniwati \\ Department of Elementary Teacher Education, Universitas Negeri Jakarta \\ Corresponding author:yurniwati@unj.ac.id
}

\begin{abstract}
In mathematics, there is conceptual and procedural knowledge. Conceptual knowledge is about ideas or mathematics understanding but procedural knowledge is about procedure to solve mathematics problems. Multisensory approach involve many senses like kinaesthetic, visual and auditory to gain knowledge. This research aims to find information about how to apply multisensory approach to improve conceptual and procedural knowledge of prospective teacher in Jakarta State University. This action research study used Kemmis and Taggart model and implemented in two cycles. The data were collected through questionnaires and observation sheets. Then, the data was analyzed descriptively. The research results showed that the multisensory approach can enhance the conceptual and procedural knowledge of the prospective teachers. The Kinaesthetic approach was implemented in hands-on activity using concrete materials while the visual using images. The concrete materials and image provide different presentation but it helped to constructed concepts and abstraction. Furthermore, the auditory approach was developed along learning activities trough discussion to produce and clarify the ideas.
\end{abstract}

Keywords: Conceptual knowledge, Procedural knowledge, Multisensory approach

\section{Introduction}

Conceptual knowledge is knowledge about the relationship or the basic idea of a concept (Van de Walle, Karp, \& Bay-Williams, 2013). The idea underlying in a concept is an understanding or definition of a concept. A person who has conceptual understanding can identify the relationships between mathematical concepts. Conceptual understanding is marked by the question "what". Rittle-Johnson, Schneider and Star explained that conceptual knowledge leads to what is known but also to the way a concept is mastered comprehensively and related to other concepts (Rittle-Johnson, Schneider, \& Star, 2015). In other words, there is no stand-alone concept.

Conceptual understanding has a strong relationship with procedural knowledge. Students with good conceptual knowledge tend to have good procedural knowledge as well (Mahir, 2009). Students with conceptual understanding can recognize the relationship between concepts and procedures, as well as provide arguments to explain why some facts are the result of other facts. They have organized their knowledge into a unified whole, allowing them to learn new ideas by connecting ideas they already know. 
In this case, concept is an understanding that can distinguish between one concept with another concept (Suratman, 2012)

Some studies show that people with high conceptual knowledge will continually develop their knowledge and expertise in organizing previous knowledge. Conversely, those who have low conceptual knowledge will see the concept separately and need assistance to understand its connection with other concepts (Schneider \& Stern, 2010).

Van de Walle et. al.,(2013) claimed procedural knowledge as the rule or steps used to solve problems through mathematical presentation. The mathematical presentation includes symbols, notations, equations, graphs, tables, sentences and so on. The procedural knowledge is marked with the question "how". Such knowledge is determined from conceptual knowledge. Therefore, in mathematical learning, conceptual knowledge should be taught first before procedural knowledge.

Procedural knowledge directs the ability to read graphs and tables, perform geometry constructs and display non-computational skills such as rounding and grouping (Suratman, 2012). National Assessment of Educational Progress (NAEP, 2002) states that procedural knowledge is often reflected in the ability to link an algorithmic process to a given problem situation and to communicate the results of the algorithm in the context of the problem.

Both conceptual and procedural knowledge are important to students because it is crucial in problem-solving. Mathematics learning in primary schools in Indonesia more focusing on procedural knowledge than conceptual one. It could be indicated from the focus of the learning process which only emphasizes the students activities on memorizing and applying the formulas. Furthermore, the constraints in conceptual knowledge lead to the difficulty undergone by students in finding the relationship between concepts. Consequently, Indonesian students, especially at the primary school level, have high score on low order thinking but low score on problem analysis, synthesis and problem solving (TIMSS, 2015).

The teachers should develop students' conceptual and procedural knowledge through appropriate learning models or assisted by appropriate learning media. Moreover, teachers are required to have a high conceptual understanding so they will be able to bring positive changes to student's learning outcomes, especially in mathematics..The circumstances indicate that the ability of conceptual and procedural knowledge of prospective teachers should be improved. Several studies related to conceptual and procedural knowledge of teachers show prospective teachers have low score on conceptual knowledge but high scores on procedures in Algebra (Zuya, 2017). New or junior teacher explains a concept based on the procedure, while experienced or senior teacher can explains the concept based on conceptual and procedural knowledge (Khashan, 2014).

The upgrading of these capabilities can be done through a learning process that involves prospective teachers physically and mentally, so they have experiences in building conceptual knowledge and procedures. It is expected that prospective students will notice that experiences in learning lead to positive attitude, and easier and fun learning. It will encourage them to create similar circumstance in their future classes.

One of the experiential learning models is the multisensory approach. Multisensory approach a learning activity that combines two or three types of senses to gain knowledge (Rains, Kelly, \& Durham, 2008). This approach uses visual, auditory and kinaesthetic elements, which are frequently done simultaneously. These elements reinforce each other to achieve optimal learning and accommodate individual differences in learning (DfES, 2004). Learning by involving all the senses helps to strengthen student's memory. It also varies the learning process and improves students' motivation. 
The multisensory approach involves all the human senses, serving as the "path" of information to the brain. Baines (2008) explained that the physical environment and interaction between students and concrete objects that involve various sensory devices will significantly influence the quality of learning. Moreover Baines claimed that the capacity of brain cells to develop will radically form a new synaptic relationship and replace the old in response to a stimulus. Baines (2008) quotes Grand in that information processing in the brain is "compartmentalized", in which the part of the brain will be active if one speaks, hears, moves and thinks. Furthermore, human brain develops, learns and moves optimally in a multisensory environment(Shams \& Seitz, 2008).

Therefore, environment and learning process should provide the opportunity for students to grasp knowledge by using all sensory devices. In fact, people live in a multisensory environment as well. Arends and Kilcher (2010) recommended the use of various expressions and different senses in learning. It will stimulate the senses and the growth of connections on the brain nerve. Verbal information causes interaction with the temporal lobe, and visual information affects the connections in the occipital lobe.

Some studies conclude that multisensory approach is essential because the integration of multiple senses provides many significant advantages (Yildirim \& Jacobs, 2012). For example, the integration of the senses gives more impact than the involvement of one sense. Likewise, the use of concrete objects as learning tools will trigger more ideas than just of pictures. The emergence of a variety of ideas leads to communication, eventually, the more communication, the more ideas or opinions. This finding is consistent with the Wozny, Beierholm, \& Shams (2008) that presented subject with visual, auditory and tactile provide numerous perceptions.

Furthermore, Yildirim \& Jacobs (2012) concluded that multisensory environment supports the learning process better than unisensory environment. Unisensory environments merely involve one of the audio, visual or tactile senses. Learning in such environment is less efficient because it is less natural and incapable of creating an optimal learning climate in compared with multisensory environment. In addition, there is a kind of unconformity in unisensory learning with the reality that automatically leads to the preference of multisensory environment.

The implications of multisensory approach in mathematics are as follows:

1. Kinaesthetic is learning by using concrete materials. Students hold, change, shape and assemble props into a concrete model of a mathematical concept.

2. Visual is transferring the concrete models into a picture. Visual is not limited to the shape of the image but can also be developed into a form of charts, tables, diagrams, etc.

3. Auditory is a discussion of fellow students, presentations, peer teaching, etc.

Multisensory approach are in accordance with the views of constructivism. They prioritize the learning process and the method provides an opportunity for students to find concepts through discovery and exploration. Exploratory activity takes place in a group setting. Interactions occur in the group will develop the potential for critical thinking, analysis and synthesis.

The previous study used different kind of material in multisensory model application like computational model (Wozny et al., 2008; Yildirim \& Jacobs, 2012). This study uses concrete material to present mathematics ideas on developing conceptual and procedural knowledge of prospective teachers.

\section{Research Methods}

The present research was conducted in Elementary Teacher Education, Universitas Negeri Jakarta, Indonesia, in academic year 2017/2018. This study used Action Research 
technique because the study was aimed at improving the effectiveness and efficiency of educational practices. Action research is a way to promote a cyclical process of improvement that includes describing a problem, seeking knowledge from previous investigators, collecting data, devising and implementing a strategy for change (Bobrakov, 2015). Over the past decade, research has been widely accepted as a means of professional development and has therefore been integrated into a growing number of teacher training programs worldwide (Burns, 2014).

The design of intervention used Kemmis and McTaggart's model (1988). Every cycle have four phases: planning, action, observation and reflection. The study was conducted in two cycles. The first cycle discussed about fractions concepts and fraction operations. Participants used colourful square paper and concrete materials available at school. The use of objects at school aims to give a message to students that any object can be used as a mathematical tool. Hence, the creativity of the teacher is required.

The second cycle discussed properties of shapes. This session used potatoes, carrots and stick. Potatoes and carrots were diced and used as a vertex connecting the stick to make shapes.

In both cycles, multisensory approach was implemented with steps as follows:

1. Problems statement,

2. Prospective teachers to solve problems with learning tools in groups,

3. Students present the problem in three kinds of representation, namely concrete model, picture and symbol.

The lecture process was recorded and the video was played back after the lesson. Subsequently, it was continued with reflection together with students about the learning progress that had been done. Data were collected along with learning process, while lecturers provided feedback directly to enhance students' understanding.

\section{Results and Discussion}

The results of research will be described in two cycles. In first cycle, multisensory approach was applied to fraction concept and fraction operations. Participants were grouped, and each group got a set of colourful square paper. The session was started by developing fraction concept through modelling, visual and square paper. For developing fraction concepts, the part-hole construction was utilized. For example, in terms of participants, they were inquired what male or female fraction in the classroom. Subsequently, the participants were questioned, whether red square papers or yellow square papers were used. Finally, participants determined what fraction of part-hole shading region.

Previously, some participants relatively had misconception on fraction. According to them, fraction is numerator that is divided by denominator. After they did some activities with square paper, participants built deep understanding on fraction concepts and connected ideas. In this case, multisensory approach helps student in constructing conceptual knowledge.

The next activity was equivalent-fraction. Participants had to find out what equivalent-fraction of $\frac{1}{4}$. Participants divided the square vertically into four parts and shading one part. The paper was folded horizontally in the middle and opened up again. Participants were questioned what fraction for shading region? Subsequently, the square paper was folded horizontally in the middle and it showed that $\frac{1}{4}=\frac{2}{8}$. In the same way, the paper was folded again horizontally and it showed that $\frac{2}{8}=\frac{4}{16}$. The participants were asked, can you explain why you have to multiply denominators and numerators with the same number to get equivalent-fraction? One of the participants answered: 
based on the fact, we have $\frac{1}{4}=\frac{2}{8}$. It means that there were connections between 1 and 2 , and 4 and 8 . To get 4 and 8 , we had to multiply 1 and 2 by 2 . The participants can explain very well, because they proved shaded area for $\frac{1}{4}$ and $\frac{2}{8}$ are the same. They were connection between denominators and numerators, multiply or divide by the same numbers.

$$
\begin{aligned}
\frac{1}{4} & =\frac{1 \times 2}{4 \times 2}=\frac{2}{8} \\
\text { and, } \quad \frac{4}{16} & =\frac{4: 2}{16: 2}=\frac{1}{8}
\end{aligned}
$$

Using concrete objects makes it easy for students to understand conceptual knowledge of equivalent-fraction, which is based on the similarity of shaded areas. Folding the square paper is similar to multiplying the denominator by the number so that the denominator also increases. Thus the process carried out on kinaesthetic activity is identical to the process carried out in a symbolic manner. Concrete manipulation of objects in exploring mathematical concepts (Sarama \& Clements, 2009), helps students relate physical experience to mathematical concepts (Kamii, Lewis, \& Kirkland, 2001)and correct missconception (Furner \& Worrell, 2017). In addition, manipulated concrete materials help to change concrete representations into abstract representations (Kamina \& Iyer, 2009).

The activity was continued to the visualized mixed number. Participants were asked about the visual form and how to determined equivalent-fraction of $1 \frac{1}{4}$. Participants made concrete model and continued by creating an image of the model (Figure 1).

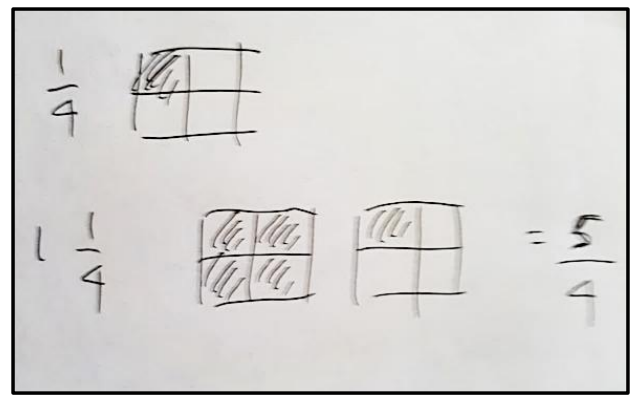

Figure 1. The visual of $1 \frac{1}{4}$

Based on visual model, participants found the procedures of $1 \frac{1}{4}=\frac{4}{4}+\frac{1}{4}=\frac{5}{4}$.

From the activities undertaken by the students about converting mixed numbers into a common fraction, it can be claimed that the order of presentation of mathematical material always begins with conceptual followed by procedural understanding. Conceptual knowledge leads to the development of strategies or procedures to solve problems.

The next topic is the addition of fractions. It started by the addition of fractions that have a like denominator. In this case, participants can solve and explain problems visually by using square paper. Problems arise when discussing addition of fractions for an unlike denominators. Participants were required to solve $\frac{1}{2}+\frac{1}{3}$ using square paper. Subsequently, they used part-hole and shaded region for $\frac{1}{2}$ and $\frac{1}{3}$. Finally, the participants were interviewed ( $\mathrm{I}=$ interviewer, $\mathrm{P}=$ participant $)$. 
I : Can you guess, if we ask primary students to answer such a question, what their answer will be?

$\mathrm{P}(1)$ : It will be $\frac{2}{5}$. Is it true? Of course not.

I : Ok, what is your solution?

$\mathrm{P}(1): \frac{5}{6}$

I : Can you explain it using concrete material?

None of the participants could answer the question, hence the following questions were posed:

I : Is the area of each square paper similar? Can we add two fractions if the shading region is not equal?

$\mathrm{P}(2):$ No.

I : Do you know why?

$\mathrm{P}(2)$ : I don't know.

I : Do you remember, can we add 2 oranges and 3 bananas?

$\mathrm{P}(2)$ : No we can't.

I : why?

$\mathrm{P}(2)$ : Because the fruit is not the same.

I : Now you know that we can add $\frac{1}{2}+\frac{1}{3}$ directly. What can we do sothat both square papers have equal region?

Participants attempted to fold the square paper similar to what they did before equivalent-fraction.

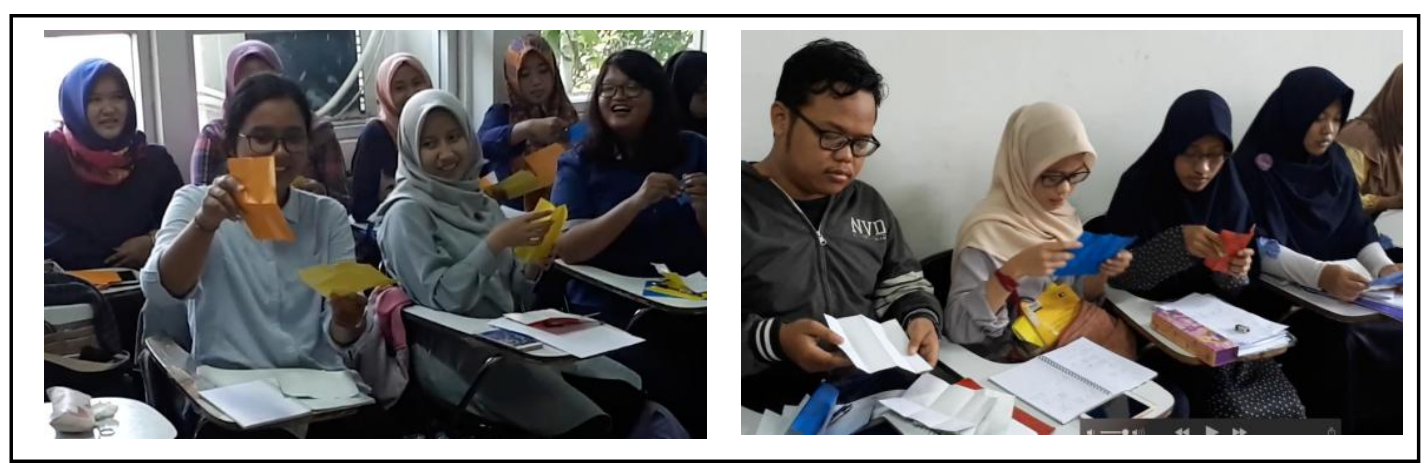

Figure 2. Students created concrete models of addition $\frac{1}{2}+\frac{1}{3}$.

After several attempts, the participants finally found a way, namely by folding the square paper 3 times for $\frac{1}{2}$ region and twice for $\frac{1}{3}$ (Figure 3 ). 


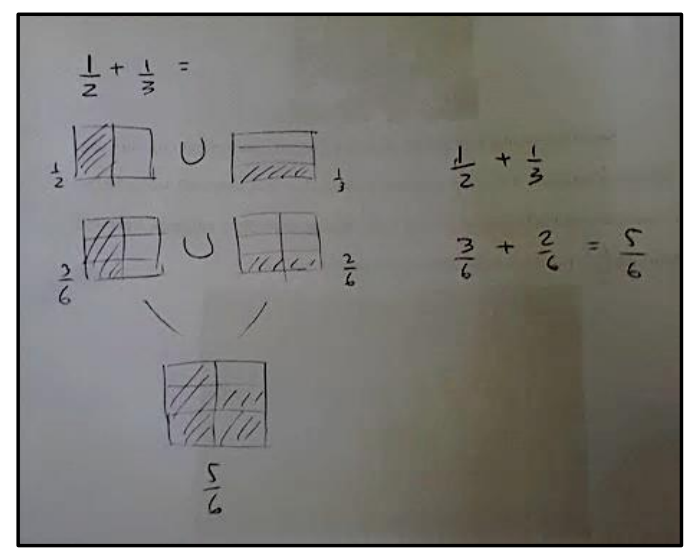

Figure 3. The visual form of the sum of fractions $\frac{1}{2}+\frac{1}{3}$.

Based on the picture, the participants were required to design the procedural of addition. One of participants wrote: $\frac{1}{2}+\frac{1}{3}=\frac{3}{6}+\frac{2}{6}=\frac{5}{6}$.

In this case, multisensory approach provide the participants an opportunity to understand conceptual knowledge through kinesthetic activities using square paper and visual model. Concrete models helps participants to grasp addition concepts. Addition in fraction is "join action" like in whole numbers as well. So participants join shaded area together, but there was a problem, $\frac{1}{2}$ and $\frac{1}{3}$ have different-size parts. So, participants need to find a way to make the shaded area have equal-size. They can solve the problem by using equivalent-fraction they had learned before.

If participants learned fraction addition on different denominator without using kinaesthetic activities, or just procedural knowledge, they don't understand why the denominator must be the same and how to find the new nominators (in his case is " 6 "). Beside, participants had experience that every step in kinaesthetic activities corresponded to procedural knowledge as show in Figure. 2.

After that, students try to present addition by drawing square in blackboard. Picture is one of semiotic representations (words, concrete materials, pictures and symbols). In this case, participants use fraction addition in different representation. Semiotic representation plays an important role in the acquisition of knowledge and knowledge transferred (Pino-fan, Guzmán, Duval, \& Font, 2015).

In the second cycle, learning activities were carried out for properties of shapes. Students learn in groups, create model for shapes and find out their properties. The participants were divided into six groups: square, rectangle, triangle, rhombus, trapezoid and parallelogram. Potatoes, carrots and sticks were distributed to the groups. The participants worked in group to discuss and determine the length of shapes, and also their properties. After 30 minutes of discussion, they had to present their findings. The statement posed by the square group is:

\section{$\mathrm{P}(3)$ : The square has four vertices, having the same four sides and can be cut into two triangles, the angle of the elbow is 4 (four). It has two pairs of parallel sides.}

Based on the statement, it can be recognized that the student still do not understand the properties of square. $\mathrm{P}(3)$ mentions the shape of square changes when it is cut in half. The following questions and answers can illustrate the group's view: 
I : Can we change the form of the square?

$\mathrm{P}(4) \quad$ : No, we can't.

I : Well then, what do you see on a square?

The participant thought for a moment, then said:

$\mathrm{P}(4)$ : The square has four right angles, four equal sides of length and two pairs of parallel sides.

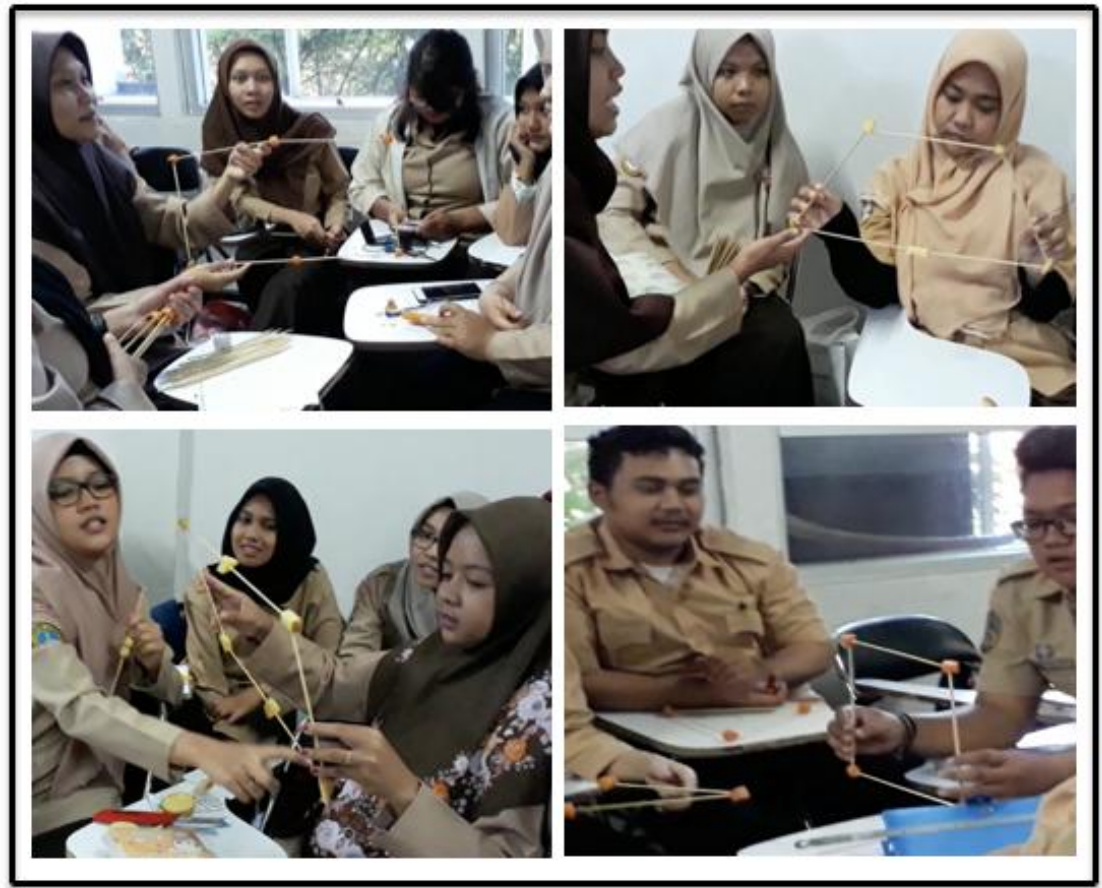

Figure 4. Group discussion.

The presentation proposed by the triangular group is as follows:

$\mathrm{P}(2)$ : Triangles have three sides of equal length, yet they can be un-equal too.

They have three vertices. The sides are not parallel and the angle is $180^{\circ}$.

I : Do we need to mention the length of the sides? Are the properties suitable to all triangles?

$\mathrm{P}(2) \quad$ : For all triangles.

I : What about parallel side? Do we need to mention it?

I : So what is the nature of the triangle?

$\mathrm{P}(2) \quad$ : Basically, triangle has three vertices and three sides.

The statement formulated by trapezoid group is as follows:

$\mathrm{P}(3)$ : The trapezoid has long sides and short sides, having two opposite sides together. There are two equivalent angles, two sloping sides with perpendicular line. Trapezoid also has asymmetrical line and one rotation symmetry.

There were several incorrect points. The students claimed that trapezoid has two sloping slides, perpendicular line and one rotation symmetry. This misunderstanding 
could be happened because teacher only use visual models. Teacher draw trapezoid in blackboard as in Figure 5. But if the trapezoid is rotated, it will be like the trapezoid in Figure 6.

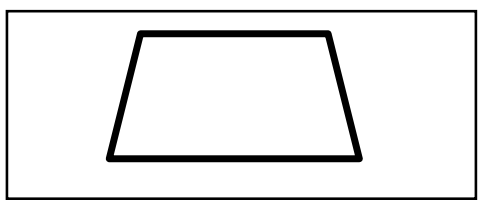

Figure 5. Trapezoid

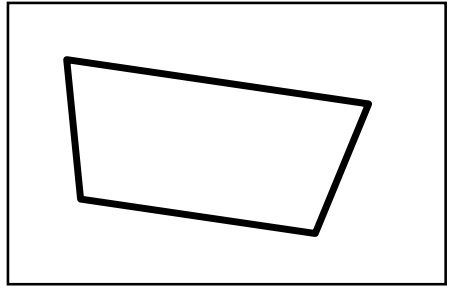

Figure 6. Rotated trapezoid

Now all of them sloping slides. Trapezoid in real life dynamic so, it can not said that trapezoid have two sloping slides.

To improve their understanding, they were asked to demonstrate two lines that are perpendicular. Nevertheless, they could not perform it. For rotation symmetry, they were asked to make two identical trapezoids and put them together. Subsequently, they turned around up triangle. The shape becomes the same to its initial shape after turning around $360^{\circ}$. Briefly, trapezoid does not have rotation symmetry. The presentation of rectangular group is as follows:

\section{$\mathrm{P}(4) \quad$ :Rectangle has the same sides. Top and bottom, left and right. It has four} corners, four sides and two line symmetry.

Rectangle group still mentioned the properties of the shape based on positions, such as top, bottom, left and right. Furthermore, a question was posed to rectangle group as follows:

I : Is the right side position always on the right? If the rectangle is turned around $90^{\circ}$, is that side still on the right?

$\mathrm{P}(4) \quad$ : No.

Some of the participants do not understand the properties of shapes. In fact, they never have experience with learning tools. So far, they only receive information from teacher and use memorization method. Learning mathematics by employing concrete materials is less common. Basically, students assume that the position of shape is static, because they see the figure in the same direction.

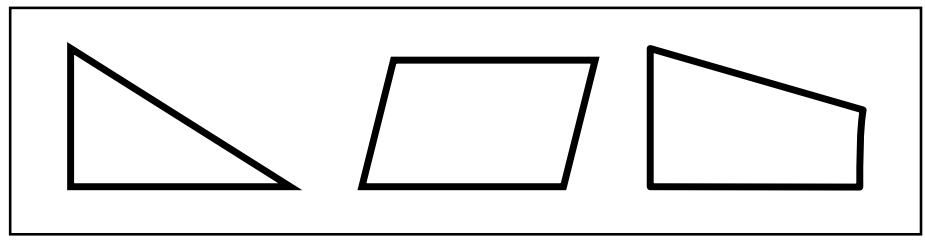

Figure 7. Shapes Orientations

Right-angled triangles are generally in the "L" position. Parallelogram and trapezoid are always inclined toward the right. In reality, all the shapes are dynamic (Figure 8). 


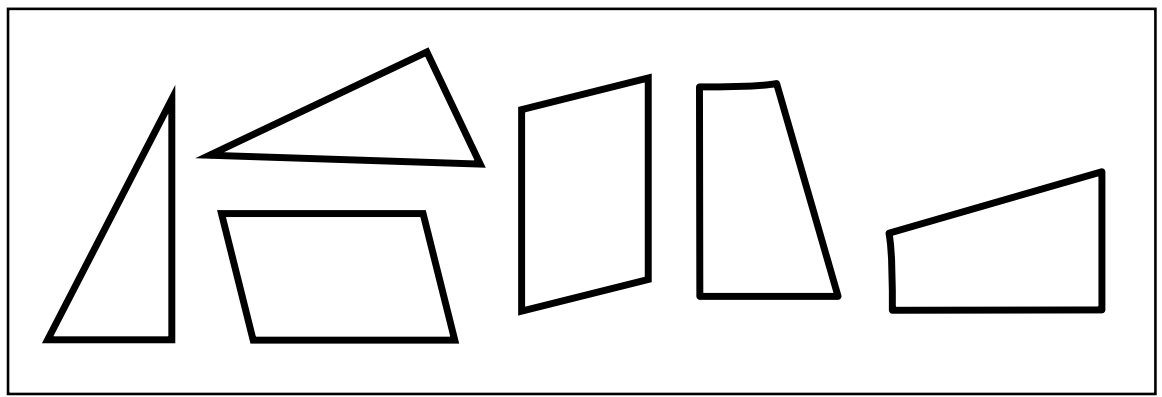

Figure 8. Shapes orientation in real life.

Finally, participants made three dimensional shapes using potatoes, carrots and sticks. The three dimensional shapes were used to discover Euler's Formula. The participants counted the number of faces $(F)$, vertices $(V)$ and edges $(E)$ of each shape. They examined the pattern until finding that $\mathrm{F}+\mathrm{V}-\mathrm{E}=2$

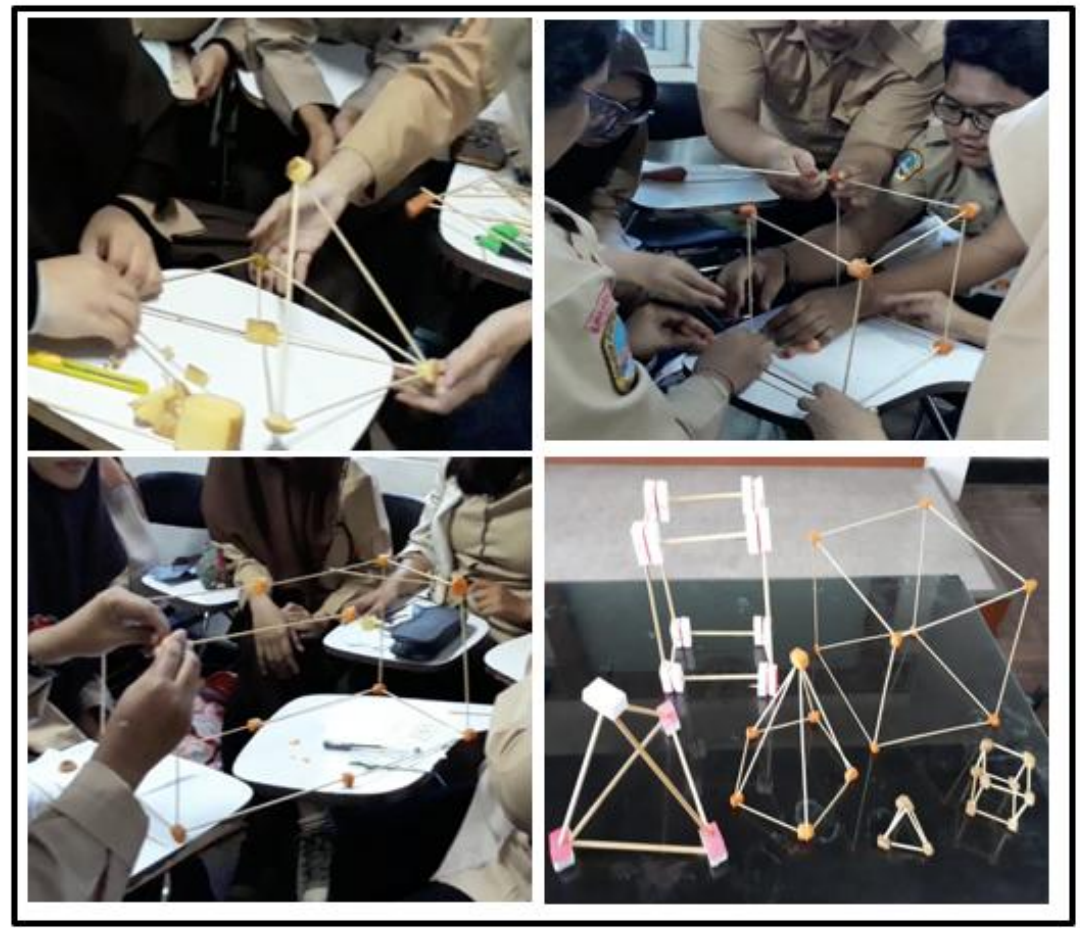

Figure 9. The construction of three dimensional shapes

The audio aspect of multisensory is when students discuss. Discussion occur between them are productive because finding information based on activities (Sfard et al., 1998). Students will listen to other's opinion and give feedback. Communication will clarify and sharpen their knowledge. Moreover, peer tutoring will enable students to understand and comprehend new concepts.

Finally, through this research, it can be argued that students' conceptual and procedural knowledge can be improved through the Multisensory approach. As prospective teacher they have the responsibility to make learning like math and can understand mathematical concepts easily. Their experience of learning with multisensory models they can use and apply to their students later. 


\section{Conclusion}

Based on the results of the study it can be concluded that multisensory approach are useful in learning abstract concepts even for adolescent. In learning mathematics concepts, it should be started from conceptual understanding and followed by procedural knowledge. Conceptual understanding is done through concrete materials, visual and symbolic notations. Kinaesthetic aspects of multisensory approach are carried out with the use of visual aids in which students are involved individually or in groups. Visual aspect of multisensory approach is carried out by displaying a model of the image and using model to develop conceptual knowledge. Auditory aspects are implemented in the form of interaction between students when working in groups.

\section{Bibliography}

Arends, R.I.,\& Kilcher, A. (2010). Teaching for students learning. New York: Routledge. Burns, A. (2014). Action research in second language teacher education. In A. Burns \& J. C. Richards (Eds.), The Cambridge guide to second language teacher education (pp. 289-297). Cambridge, UK: Cambridge University Press.

Baines, L. (2008). A Teacher's Guide to Multisensory Learning. Alexandria: ASCD. Retrieved from

http://www.lawrencebaines.com/uploads/5/3/5/1/53511551/multisensory_book _chapters_1-2_by_baines.pdf

Bobrakov, S. (2015). a Foreign Language Teacher, 34-41.

DfES. (2004). A Framework for Understanding Dyslexia. DfES. London: Department of Education and Skills. Retrieved from www.dfes.gov.uk/readwriteplus/understandingdyslexia

Furner, J. M., \& Worrell, N. L. (2017). The Importance of Using Manipulatives in Teaching Math Today. Transformations, 3(1). Retrieved from http://nsuworks.nova.edu/transformations\%0Ahttp://nsuworks.nova.edu/transfo rmations/vol3/iss1/2

Kamii, C., Lewis, B. A., \& Kirkland, L. (2001). Manipulatives: When are they useful? Journal of Mathematical Behavior, 20(1), 21-31. https://doi.org/10.1016/S07323123(01)00059-1

Kamina, P., \& Iyer, N. (2009). From Concrete to Abstract: Teaching for Transfer of Learning when Using Manipulatives. NERA Conference Proceedings 2009, 6. Retrieved from papers://3a07567f-5013-4eec-86cd-a5ef539fd065/Paper/p1609

Khashan, K. H. (2014). Conceptual and Procedural Knowledge of Rational Numbers for Riyadh Elementary School Teachers. Journal of Education and Human Development, 3(4), 181-197. https://doi.org/10.15640/jehd.v3n4a17

Mahir, N. (2009). Conceptual and procedural performance of undergraduate students in integration. International Journal of Mathematical Education in Science and Technology, 40(2), 201-211. https://doi.org/10.1080/00207390802213591

Pino-fan, L. R., Guzmán, I., Duval, R., \& Font, V. (2015). The Theory of Registers of Semiotic Representation and the Onto-Semiotic Approach To Mathematical Cognition and Instruction: Linking Looks for the Study of Mathematical. 39th Psychology of Mathematics Education Conference, 4, 33-40.

Rains, J. R., Kelly, C. a, \& Durham, R. L. (2008). Multi-Sensory Teaching Techniques in Elementary Mathematics : Theory and. Journal of Theory and Practice in Education, 4(2), 239-252. Retrieved from https://www.uccs.edu/ Documents/coe/people/faculty/kellyc/MultiSensoryTec hniques.pdf

Rittle-Johnson, B., Schneider, M., \& Star, J. R. (2015). Not a One-Way Street: 
Bidirectional Relations Between Procedural and Conceptual Knowledge of Mathematics. Educational Psychology Review, 27(4), 587-597. https://doi.org/10.1007/s10648-015-9302-x

Sarama, J., \& Clements, D. H. (2009). "Concrete" computer manipulatives in mathematics education. Child Development Perspectives, 3(3), 145-150. https://doi.org/10.1111/j.1750-8606.2009.00095.x

Schneider, M., \& Stern, E. (2010). The Developmental Relations Between Conceptual and Procedural Knowledge: A Multimethod Approach. Developmental Psychology, 46(1), 178-192. https://doi.org/10.1037/a0016701

Sfard, A., Nesher, P., Streefland, L., Cobb, P., \& Mason, J. (1998). Learning mathematics through conversation: Is it as good as they say? For the Learning of Mathematics, 18(1), $41-51$.

Shams, L., \& Seitz, A. R. (2008). Benefits of multisensory learning. Trends in Cognitive Sciences, 12(11), 411-417. https://doi.org/10.1016/j.tics.2008.07.006

Suratman, D. (2012). Learning to learn. Cakrawala Pendidikan, 16(6), 13-16. Retrieved from http://jurnal.untan.ac.id/index.php/jckrw/article/view/145

Van de Walle, J. A., Karp, K. S., \& Bay-Williams, J. M. (2013). Elementary and Middle School Mathematics Teaching Developmentally. Boston: Pearson.

Wozny, D. R., Beierholm, U. R., \& Shams, L. (2008). Human trimodal perception follows optimal statistical inference. Journal of Vision, 8(3), 24. https://doi.org/10.1167/8.3.24

Yildirim, I., \& Jacobs, R. A. (2012). A Rational Analysis of the Acquisition of Multisensory Representations. Cognitive Science, 36(2), 305-332. https://doi.org/10.1111/j.1551-6709.2011.01216.x

Zuya, H. E. (2017). Conceptual and procedural knowledge in mathematics: The Case of Mathematics. Amarican Journal of Educational Research, 5(3), 310-315. https://doi.org/10.12691/education-5-3-12 